\title{
El entretenimiento del pasado: El radioteatro porteño y su alianza con el sainete criollo
}

\section{(4) Constanza Grela Reina}

Facultad de Filosofía y Letras, Universidad de Buenos Aires, Argentina

constanzagrela@gmail.com

Fecha de recepción: 30/03/2018. Fecha de aceptación: 19/04/2018

\begin{abstract}
Resumen
En la década del treinta, en medio del agitado clima político y social tiene surgimiento el radioteatro porteño, expresión que rápidamente se expande y se afianza como forma de entretenimiento popular. El mismo, es el resultado de la fusión de diversos géneros que ya estaban consolidados y que habían comprobado su eficacia ante las grandes audiencias, entre ellos tenemos el sainete criollo, el melodrama y el folletín. Nos proponemos entonces demostrar las relaciones de retroalimentación entre dichos géneros y el radioteatro porteño. El objetivo, es además, rescatar la memoria de las expresiones populares que entretuvieron a nuestros predecesores.
\end{abstract}

\section{Entertainment of the Past: Radio Drama and its Collaboration with the Sainete Criollo}

\begin{abstract}
Radio drama emerges in Buenos Aires in the thirties, in the midst of a hectic political and social context, and it quickly consolidates itself as a form of popular entertainment. It is the result of the fusion of diverse genres that were already established and that had already proven their effectiveness with large audiences, such as the sainete criollo and melodrama, amongst others. This article seeks to demonstrate the relations of mutual feedback between these genres and the radio theater of Buenos Aires. The purpose is also to rescue the memory of the popular expressions that entertained our predecessors.
\end{abstract}

\section{Introducción}

La relevancia de este trabajo radica en la necesidad de explorar temas de la cultura y el arte argentino que han sido dejados de lado durante varias décadas, por ser
Palabras clave

Radioteatro; Sainete criollo; Géneros populares; Cultura de masas; Entretenimiento

Keywords

Radio Drama; Sainete Criollo; Popular Genres; Mass Culture; Entertainment 
considerados periféricos o de nulo interés. Creemos en la necesidad de redireccionar la mirada hacia estos ejes con la esperanza de revigorizar las discusiones y debates sobre la cultura popular.

Este trabajo se propone estudiar la relación de dependencia y estimulo entre el radioteatro porteño y el sainete criollo. Nuestra hipótesis es que el radioteatro es el resultado de la fusión de diferentes manifestaciones artísticas entre las que son fácilmente reconocibles el sainete criollo, como asimismo, el circo criollo y el teatro popular del Rio de la Plata, géneros que se caracterizan por su contenido popular altamente adaptable a los gustos heterogéneos del público. Además pretendemos demostrar que esta relación no fue solamente de aprehensión de estrategias por parte del radioteatro, sino que fue de retroalimentación.

El objetivo será entonces, comprender los procesos que hacen de ésta manifestación un suceso popular y masivo sin precedentes, como también indagar acerca de la recepción y sus pautas de consumo, las cuales se encuentran íntimamente relacionadas con las del sainete criollo. En consecuencia, demostrar cómo el radioteatro conformó una nueva forma de cultura de masas, gracias a la yuxtaposición de diversas estrategias procedentes de géneros populares y, de igual modo, explicitar la relación de intertextualidad existente con el sainete.

Para ello utilizaremos como maco teórico al referirnos al radioteatro, principalmente los estudios realizados por Manuel Maccarini y (2006) y Carlos Ulanovsky (2004). En el caso del sainete criollo y el teatro popular se tomará de referencia los aportes realizados por Osvaldo Pellettieri (2008). Finalmente, para referirnos a las teorías sobre cultura de masas utilizaremos las formulaciones realizados por Alejandro Blanco (2002).

\section{El radioteatro porteño y el sainete criollo de los años 30}

Es indispensable mencionar algunas palabras respecto del contexto histórico en el que se encontraba la Argentina. Los años 30 fueron un período de gran agitación social, tanto a nivel local como mundial. La crisis internacional desencadenada por la gran depresión en los Estados Unidos deterioró la economía y los niveles de vida de los sectores populares, que se extendió a varios países del mundos impactando de manera negativa en varios países latinoamericanos, entre ellos Argentina. Además de esto, en nuestro país, en dicho periodo, se produjo el primero de los golpes de Estado que azotaron a nuestra democracia. ${ }^{1}$

En este contexto el radioteatro surge entre los años 1931 y 1932 con la aparición de conjuntos como "Chispazos de tradición", considerado uno de los fundadores del género. La aparición de la radio en Argentina había comenzado solo una década atrás, en el año 1920, con la primera transmisión realizada desde la terraza del Teatro Coliseo, de la opera Parsifal de Richard Wagner, a manos de Enrique Susini, Miguel Mujica, Cesar Guerrico y Luis Romero Carranza, conocidos como "los locos de la azotea" (Matallana, 2006:14). A partir de este hito, la industria radiofónica se va desarrollar de una manera veloz con la consolidación de las primeras emisoras; Radio Splendid, Radio Nacional y El Mundo. Además, se multiplica la cantidad de trasmisores en poder de los radioescuchas. En efecto, Cecilia Gil Mariño (2015) señala que luego de la primera transmisión de radio se registraron mil receptores, mientras que hacia fines de 1936 la cifra ya ascendía a un millón y medio (38). La trayectoria de la radio argentina es incomparable, ya que su desarrollo, evolución e influencia prácticamente no tiene precedentes en el mundo.
1. El 6 de septiembre de 1930, tiene lugar el primer golpe de estado en Argentina. Un grupo de militares, encabezado por el General José Félix Uriburu, derroca al Presidente electo Hipólito Yrigoyen, estableciendo así una dictadura militar. En este periodo se profundiza la crisis económica que impactaba en el país, produciéndose la caída de los precios de las materias primas, el principal ingreso de la Argentina. 
Paradójicamente, mientras el mundo entra en recesión, la radio alcanza un impulso notable y, junto con ella, el nuevo género del radioteatro, en tanto, en el sector teatral, las expresiones populares como el sainete y el grotesco estarán en apogeo. En consecuencia, es posible arriesgar la hipótesis de que el éxito existente de estas expresiones se encuentra en relación con la necesidad de un pueblo adolorido que desea encontrar una vía evasora a la realidad social.

Uno de los precursores del radioteatro fue el inmigrante español José Andrés González Pulido, quien conformó el ya mencionado conjunto "Chispazos de tradición". La agrupación llevó adelante numerosos radioteatros ${ }^{2}$ que significaron un verdadero fenómeno de audiencia, y es a partir de ese momento que la ficción en radio se posicionó como una nueva forma de espectáculo. "Por el empeño de González Pulido y su troupe, la popularidad del género explota y deja marcas para siempre. José Andrés González Pulido, llamado el 'Tata Grande', es pionero indiscutido del radioteatro, inmigrante acriollado lleno de inventiva y audacia" (Ulanovsky, 2004:74). Es aquí cuando se comenzará a especializar la producción del género, instalando diversos tipos y clasificaciones según la temática y el contenido.

Manuel Maccarini realiza un análisis sobre el radioteatro, pero también sobre los géneros sainete y circo criollo con los que, según su hipótesis, se encuentra íntimamente relacionado. En su trabajo realiza una caracterización global del género, indiciando sus principales características y mecanismos. Subraya su capacidad revolucionaria, como también su contenido popular altamente adaptable a los diversos gustos del público. Así afirma: "La radiofonía fue un medio de comunicación que revoluciono a la sociedad porteña. Poco a poco su influencia se extendió. Las emisoras proliferaron por todo el territorio. En este medio se gestó el radioteatro que, como arte, integró el pensamiento popular" (Maccarini, 2006:70).

Por su parte, el sainete criollo, que ya había atravesado todas sus fases ${ }^{3}$ y sus diferentes versiones, se encontraba establecido y gozaba de gran popularidad y audiencia. El mismo tuvo su origen en el año 1770 aproximadamente con El amor de la estanciera, de autor anónimo, teniendo luego intermitencias, hasta que finalmente en el año 1884 con el estreno de Juan Moreira de Eduardo Gutiérrez y José Podestá se estableció como forma de representación popular de gran repercusión y circulación (Pellettieri, 2008: 11-12).

Pensamos la coexistencia del sainete criollo y el radioteatro desde una perspectiva integradora que concibe a ambas manifestaciones de manera complementaria, es decir, no como la influencia de uno sobre otro, sino desde una concepción de estimulación entre ambos. En este sentido, creemos que tanto el teatro, como la radio, la literatura y el cine se configuran como partes de un todo en el que no existe división alguna, ya que conviven en el mismo universo cultural y se interrelacionan entre sí constantemente.

\section{Signos de intertextualidad}

Según señala Maccarini (2006), el funcionamiento de las agrupaciones radioteatrales era similar al de las viejas compañías teatrales y al del circo. Los elencos se encontraban organizados en torno a una cabeza de compañía, quien era el ideólogo, dramaturgo y libretista generalmente.

En la función autoral tiene el radioteatro su más importante razón de ser. Se trata de hombres representativos de su medio social, antes actores, después directores y finalmente escritores que privilegiaban al género en todo su conjunto. En muchos casos eran movilizados por objetivos meramente mercantilistas. (73).
2. Entre sus títulos figuran: La estancia de Don Segundo, ¡Por la señal de la cruz!, El secreto de Churrinche, ¡Dudas!, El Alma de la Gauchita, El fogón de los gauchos, Cuando los criollos son criollos, Al calor de los cariños, El matrero de la Luz!, y iEl puñal de los centauros! En la Biblioteca Nacional se encuentran disponibles algunas de las ediciones de guiones por episodios de la novela gaucha y algunos folletines (edición impresa) del radioteatro emitido. Dichas publicaciones fueron realizadas por los editores Briozzo Hnos.
3. Osvaldo Pellettieri propone una interesante clasificación del genero saineteril, afirma que el mismo posee tres fases: sainete como pura fiesta - fase primaria, ingenua o intuitiva- cuyo ejemplo encontramos en Fumadas de 1902 de Enrique Butaro; sainete tragicómico -fase secundaria o canónica, aquí se consolidan las reglas del genero con obras como Los disfrazados de 1906 de Carlos Mauricio Pacheco; y el grotesco criollo -fase de reversión total de la forma secundaria- donde se localizan varias obras de Armando Discépolo, como Stefano de 1928. 
Y al igual que en las obras de las viejas compañías, cada personaje era diseñado como un arquetipo, compuesto por características modélicas y fuertes personalidades entre las que se destacaban personajes como el gracioso, el héroe, el villano, la dama joven, el galán, etc. Siguiendo la idea de Maccarini "En la escenificación, el radioteatro se emparentaba con la commedia dell, arte. Cada personaje era un arquetipo y llevaba consigo un arsenal de recursos repetibles de obra en obra" (2006:73). Lo cual es igualmente observable en la configuración de los personajes y la actuación de las obras del sainete criollo, ya que ambos comparten los mimos códigos de representación.

Los episodios radioteatrales constaban de una emisión en la que tenía lugar no solo el drama y la actuación de los personajes, sino que había música, canciones, payadas y pasos de comedia. Asimismo, esto se encuentra presente en las representaciones de las compañías saineteras, a menudo las obras contaban con la presencia de música, canciones y especialmente tangos.

En cuanto a la actuación, Osvaldo Pellettieri sostiene que el actornacional4 se construyó a partir de una serie de roles básicos y que "entre las tendencias que integran su patrimonio artístico se destacan los procedimientos y técnicas circenses, las técnicas del actor cómico italiano y las del naturalismo" (Pellettieri, 2008:220). En este tipo de actuación, el actor debía estar muy atento a su auditorio, ya que adaptaba su actuación a las necesidades y solicitudes del público. El principal objetivo era entretener y divertir, por lo tanto el resto de signos escénico quedaba subordinado a la actuación. "El sainete es un género teatralista. Es decir, le muestra al público que aquello que está viendo es 'teatro'. Evidencia la forma de actuación, busca que la música y las canciones le recuerden al público que está en el teatro" (Pellettieri, 2008:76). Este tipo de actuación fue compartida por el radioteatro. Maccarini afirma que "elencos y actores cambiaban los códigos para abarcar a un estadio cultural diseminado en la totalidad del territorio, estableciendo lazos entre los cuatros extensos puntos cardinales" (2006:70). En este mismo sentido, sostiene que el actor radioteatral tenía una visión total de su país, gracias a su contacto gira a gira por todas las provincias.

En lo que respecta a la intención creativa orientada hacia el público, el radioteatro y el sainete se encuentran profundamente relacionados. En parte los autores, pero especialmente los actores cabeza de compañía, se encontraban empeñados en lograr una obra que fuera resultado de un diseño minucioso, que asegurara captar y conservar al mayor y más amplio público posible. En ambos casos, el fin era principalmente el rédito económico, más que el lucimiento estético.

En relación a esto, es destacable la palabra del autor radioteatral Gonzales Pulido, quien ilustra sus estrategias a la hora de crear sus personajes para el conjunto "Chispazos de tradición":

Mis guachos son míos. Yo los he creado al "uso nostro". No he buscado modelos de ninguna especie. Durante gran parte de mi vida he recorrido el campo argentino de un extremo a otro. Y me he encontrado con gauchos auténticos (...) No podía, pues, hacer un gaucho como los que he visto al natural. Pues éstos olían mal y no tienen nada de poéticos. En cambio yo he creado un gaucho higiénico (...) A mí, el gaucho de verdad no me convence. Es un sujeto mal hablando, borracho, ocioso y pendenciero. Sería contraproducente idealizarlo (...). No había más remedio que crear un gaucho que satisfaga las exigencias del mercado. Y esto he hecho yo (Berman, 2010:137-138).

En el caso de "Chispazos de tradición", como en muchos otros ejemplos de compañías radioteatrales, la circulación excedió la radio. En consecuencia, los elencos se presentaron en vivo en diversos cines, teatros, y hasta clubes de barrio a lo largo de todo el país.
4. Pellettieri denomina actor nacional, al actor que interpreta los géneros populares como el sainete y el grotesco, tuvo su auge entre los años 1884 y 1930. La construcción del personaje se deba a partir de arquetipos como: el galán, la dama, el cómico. El ejemplo paradigmático de este tipo de actuación es Florencio Parravicini. 
El caso paradigmático de "Chispazos de tradición" puede tomarse como un modelo del éxito extraordinario que significó el radioteatro en Buenos Aires. Con su desembarco en la radiofonía porteña se modificaron diversas costumbres en lo que respecta a la recepción; muchos de los hábitos cotidianos se adaptaron y modificaron naturalmente para poder consumir este fenómeno. Consta en revistas de la época la alteración de horarios en salas de cine, dado que coincidían con la emisión del radioteatro, como también la colocación de alto parlantes en grandes tiendas de venta para que los clientes no dejaran de ir. A su vez, es gracias al radioteatro que aparecen categorías como la publicidad radial que hasta el momento era prácticamente inexistente. Asimismo, las obras radiales tuvieron tanta trascendencia que la revista Antena abrió una sección de "Carta de Lectores" únicamente referida a "Chispazos de tradición". La circulación de este género además se realizó mediante folletines y económicas ediciones especiales realizadas con el objetivo de captar periódicamente la atención del público.

En lo que respecta al sainete, la circulación del mismo tuvo lugar en la escenificación dentro del diverso sistema de salas y teatros porteños en especial los destinados al público popular/comercial. Por otro lado, a pesar de que es muy frecuente en el medio teatral la conservación de las obras en formato libro para su subsistencia, el sainete careció de este modelo:

... aparecían en revistas como Bambalinas, La escena, El teatro Nacional, que eran de publicación semanal. [...] En el comentario de las obras- que no eran hechos por grandes artistas o universitarios- en general se criticaba a los actores que no respetaban los textos, aparecían chismes de vestíbulo, reproducciones de críticas positivas al texto, apologías al copo cómico (Pellettieri, 2008:81).

De igual modo, Osvaldo Pellettieri destaca que dentro del circuito cultural, las revistas tenían un lugar de gran relevancia social, ya que poseían un amplísimo público tanto en Buenos Aires como en los suburbios.

Una vez más queda retratada la inseparable conexión existente entre el radioteatro y el sainete en la década del 30; ambos compartían el mismo sistema de producción, circulación, pero fundamentalmente, la relevancia reside en que ambos compartían el mismo destinatario final: el público popular, conformado por clases bajas y media, inmigrantes y trabajadores, quienes disfrutaban de este tipo de espectáculos. En este sentido Pellettieri afirma:

La cultura popular fue dominando la escena artística del país en estos años, la radio formo parte de este proyecto participando como medio masivo de alcance nacional. En la radio porteña se comenzó a trasmitir obras teatrales, lo que se realizó durante largos años en la radio (2008:82).

Para referir unas últimas palabras respecto de lo que significó para las clases populares la existencia del circuito cultural popular, es interesante observar la reflexión de la escritora y dramaturga Nelly Fernández Tiscornia quien destaca una dimensión diferente del radioteatro: la didáctica, diciendo "fui alimentada a radioteatro. Nací en el campo, de una clase social para la cual llegar al libro era un gran sacrificio. Así que todo se aprendía por la radio" (Ulanovsky, 2004:75). Es destacable el gran alcance y la capacidad transformadora de este medio, la radio y su contenido, no solo el radioteatral, sino también el informativo, musical y cultural resultaron ser un instrumento, para la formación y el acompañamiento de los ciudadanos. 


\section{El radioteatro como fusión de géneros populares}

Es posible afirmar que el surgimiento del radioteatro se debe a la fusión o productividad de diferentes manifestaciones artísticas, entre las que son fácilmente reconocibles: el sainete, el circo criollo, el melodrama, el folletín, la canción popular, el tango, la payada entre otros. Todos son géneros eminentemente populares que concentraban su atención en el gusto del público de manera de maximizar los resultados económicos. Los géneros con los cuales el radioteatro traza relaciones intermediales o establece préstamos ya habían comprobado su eficacia en el público en numerosas oportunidades. Estos solían utilizar un código común y compartido por los distintos sectores de una heterogénea sociedad atravesada por los cambios sociales, culturales y políticos de la década de los años 30.

Además, es indispensable señalar que el crecimiento y la evolución de la radio argentina fue de manera vertiginosa, lo cual influyó en arribo del radioteatro. A partir de la aparición de la radio en la década del 20 en Argentina, se incrementaron y diversificaron las emisiones radiales que contaron con programaciones informativas, culturales, musicales y hasta incorporaron de manera estable el formato del radioteatro, al cual le dieron una gran relevancia. Esto encuentra su demostración en que el radioteatro se instaló en la radio prácticamente de manera definitiva. Más allá de haber surgido a comienzos de los 30, continuo teniendo diferentes programas y agrupaciones que se presentaron a lo largo de muchos años, como por ejemplo, los reconocidísimos casos de "Los Pérez García", entre 1942 y 1967, y el ciclo "Las dos caratulas" que se estrenó en el año 1950 y continua hasta la actualidad, en Radio Nacional.

La relación que señalamos respecto a la utilización de géneros populares para la configuración del radioteatro fue principalmente de intercambio y colaboración y no de captación de estrategias. En este sentido, destacamos que el radioteatro también nutrió la práctica teatral proporcionando actores y promoviendo espectáculos.

Volviendo al ejemplo particular que tomamos de radioteatro, "Chispazos de tradición", Ulanovsky (2004:74) señala que González Pulido inspiró su trabajo en la payada, en el primitivo folletín, en el dramón circense, en el melodrama mazorquero y cruzó todas esas formas con el sainete. Resultado de esta intertextualidad, el radioteatro se convirtió un género tan amado como odiado, despertando numerosas polémicas y oposiciones. Manuel Macarini cita un trabajo inédito del docente Gustavo Bonamino en el que se señala la polémica que existió en torno a la creación de González Pulido, destacando las críticas del actor Zelmar Gueñol, quien catalogaba su obra de "burda, carnavalesco, inauténtico. Afirmando que si es que tiene algunas raíces de la tradición que invoca, ellas son adventicias, endebles parodias de cualquier regionalismo argentino, hibridas, toscamente definidas y hasta falsas; como su lenguaje, sus cadencias, su psicología, sus caracteres" (2006: 76).

\section{Polémica por el estatus de obra de arte}

Mientras qu el público acogió con los brazos abiertos a este tipo de manifestaciones y permitió su instalación en el escenario cultural popular argentino, tanto el radioteatro como el sainete fueron objeto de numerosas críticas y desvalorizaciones por ser considerados como expresiones de la baja cultura. El principal cuestionamiento giró en torno a su legitimación cultural y artística. Gran parte de la crítica se negó a considerar artísticamente a estas manifestaciones, clasificándolas como un género menor, mero entretenimiento pasajero e indigno de estatus artístico. 
En el caso del radioteatro, Jorge Rivera señala que el principal aspecto del que echaban mano los detractores del género era su condición masiva y popular. Para los grupos de elite, que fundan sus parámetros artísticos en el pensamiento clásico, resultaba problemático incorporar en el centro del campo cultural una manifestación con las características del radioteatro.

Los radioteatros y teleteatros se convirtieron para muchos en la auténtica "bestia negra" de los medios masivos, en una suerte de ominosa "antipartícula" que actuaría con consecuencias previsiblemente desastrosas sobre las partículas simétricas del arte, del buen gusto y de la lucidez social e individual (Rivera, 1985:46).

Mientras que ciertos críticos ven en el radioteatro una "positiva forma de liberación catártica en lo imaginario", otos lo ven, sencillamente, como una "neutra posibilidad de entretenimiento" (Rivera, 1985:47). Rivera, finalmente, señala que prevalecen las objeciones, o por lo menos las reticencias, a arrojar cierto grado de razonable duda sobre su papel cultural y social.

En lo referido al sainete, Osvaldo Pellettieri sostiene que "por largos años, desde 1900 hasta la actualidad, el sainete y sus cultores fueron la 'oveja negra' del teatro argentino. Su sola existencia explicaba todos los vicios que se le endilgaban al país" (2008:7). A través de esta reflexión es posible observar el lugar periférico destinado al teatro popular dentro del campo intelectual argentino. Al igual que el radioteatro y otros géneros populares, el sainete sufrió el desprecio de los críticos de la elite cultural y académica, por no considerar que sus elementos constitutivos fuesen valiosos. En este sentido, Pellettieri también afirma que el estudio del teatro popular siempre presenta obstáculos, dado que hay que pelear contra los prejuicios culturales.

En el campo intelectual hay posiciones centrales, marginales, excéntricas y desplazadas. En él conviven desde Borges hasta Silvio Soldán. Los saineteros con capacidad tenían un público fuera del campo pero querían ser reconocidos dentro de él (2008:50).

Dentro del sistema de producción del teatro popular y el radioteatro existen algunos agentes que ambicionan pertenecer y tomar mayor centralidad en el campo cultural, mientras que otros desean simplemente saciar sus necesidades comerciales.

Para reflexionar sobre estas manifestaciones en lo que respecta a su dimensión masiva resulta interesante indagar acerca del concepto cultura de masas. Una primera definición propuesta por Alejandro Blanco es:

Usada generalmente en términos peyorativos, la expresión designa un tipo de cultura de carácter superficial y mediocre destinada a explotar los gustos más triviales del gran público. Ejemplos típicos: novelas rosa, radioteatros, determinadas películas, comedias y espectáculos de revistas, dibujos animados, historietas, canciones, relatos de ciencia ficción, obras de divulgación (2002:42).

Esta primera definición reviste el término de una connotación negativa debido a que, entre otras cosas, son producidas y/o fabricadas por técnicos y no por artistas de la alta cultura. De igual modo, esta negatividad se debe a que era considerada una amenaza para la cultura superior. Sin embargo, esta definición fue superada gracias a que los investigadores pudieron advertir que muchos de los prejuicios que se habían realizado sobre estas manifestaciones eran equívocos.

La supuesta homogeneidad de la cultura de masas se ha visto debilitada frente al reconocimiento de la diversidad de la producción cultural en el ámbito de 
las culturas de masas. Igualmente, la innovación y la experimentación no son patrimonio exclusivo de la cultura alta. Muchos creadores de la cultura de masas aspiran a que sus productos expresen sus gustos y valores personales. Desde el punto de vista estilístico la cultura de masas es menos conservadora de lo que sus críticos habían imaginado. Ha dado originan a un conjunto de nuevos lenguajes, de nuevos modos de expresión y percepción (Blanco, 2002:43).

En la actualidad y con el paso de los años es posible afirmar que nació un nuevo interés por investigar acerca de dichas expresiones y que hoy en día son nuevamente revisitadas y valorizadas. Es necesario expresar enfáticamente que resulta imprescindible apreciar los aportes realizados por creadores del teatro popular, el sainete y el radioteatro debido a su innegable mérito cultural y artístico, que ha dejado su huella e influido en diferentes manifestaciones artísticas vigentes hasta el día de hoy.

\section{Apreciaciones finales}

En síntesis, el sainete criollo y el radioteatro porteño formaron parte del extenso universo cultural de los años treinta en Buenos Aires. Ambos compartieron numerosas características comunes, entre las que mencionamos: las formas de actuación, las formas de producción, y el mismo modelo de receptor: el gran público, las grandes audiencias. Es por esto que es posible pensar estas formas de representación como caras de una misma moneda. La notable permeabilidad existente entre ambas manifestaciones permite afirmar que se retroalimentaron mutuamente. Si bien el radioteatro surgió varias décadas después que el sainete y éste es una de sus fuentes de alimentación, una vez fundada la existencia del radioteatro, es inseparable del teatro popular. El radioteatro se consolidará como genero popular de gran productividad a lo largo de las décadas, inclusive llegando hasta nuestros días. Las matrices de representación del pasado son prácticamente las mismas que siguen hoy vigentes: el humor, el melodrama y la yuxtaposición de música y poesía.

El sainete y el radioteatro fueron acogidos por el público, que los acompañó llenando salas y siguiendo fielmente los ciclos radiales. Los hizo así parte de su vida cotidiana y de sus costumbres. Sin embargo, en lo que respecta a la crítica y las instituciones legitimantes, vimos que no encontraron interés en los géneros populares, y no hallaron en ellos relevancia cultural. Es por esto que tenemos la necesidad de reflexionar, investigar y discutir nuevamente acerca de estas variables artísticas, dado que consideramos que por muchas décadas han sido subestimadas. Creemos necesario reaccionar contra las posturas que las han dejado de lado por no considerarlas valiosas o simplemente por considerarlas en la periferia de lo artístico. Este es el momento para echar luz sobre aquellas formas artísticas que entretuvieron, divirtieron y fascinaron a nuestros antepasados. 


\section{Bibliografía}

"Berman, M. (2010). "Las huelas de la ciudad en los primeros radioteatros", Revista LIS - Letra Imagen Sonido - Ciudad mediatizada (5), 134-143.

"Blanco, A. (2002). “Cultura de masas”. En Altamirano C. Términos de sociología de la cultura, (pp. 42 -44). Buenos Aires: Paidós.

"Bourdieu, P. (1967). “Campo intelectual, y proyecto creador”. En AAVV. Problemas del estructuralismo. México: Siglo XXI.

» Gil Mariño, C. (2015). El mercado del deseo: tango, cine y cultura de masas en la Argentina de los '30. Buenos Aires: Teseo.

» Maccarini, M. (2006). Teatro de identidad popular. Buenos Aires: Instituto Nacional del teatro.

»Matallana, A. (2006). Locos por la radio. Una historia social de la radiofonía en la Argentina, 1923-1947. Buenos Aires: Prometeo.

»Pellettieri, O. (2008). El sainete y el grotesco criollo: del autor al actor. Buenos Aires: Galerna.

"Rivera, J. (1985). Medios de comunicación y cultura popular. Buenos Aires: Legasa.

»Ulanovsky, C. (2004). Días de radio 1920-1959. Buenos Aires: Emecé. 